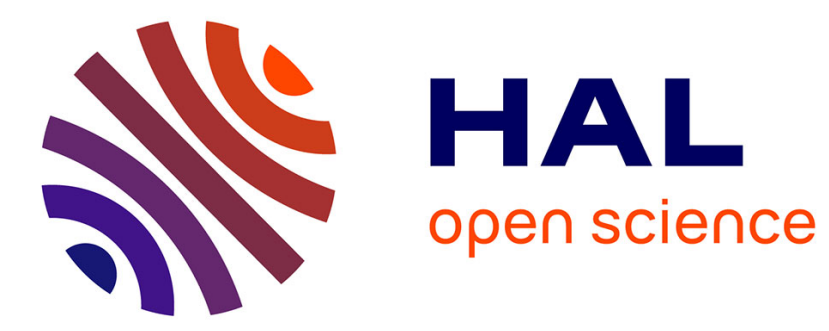

\title{
Molecular tectonics: enantiomerically pure chiral crystals based on trans -1,2-cyclohexanediol
}

Benjamin Forquin, Julien Berthaud, Abdelaziz Jouaiti, Nathalie Kyritskas, Sylvie Ferlay, Mir Wais Hosseini

\section{- To cite this version:}

Benjamin Forquin, Julien Berthaud, Abdelaziz Jouaiti, Nathalie Kyritskas, Sylvie Ferlay, et al.. Molecular tectonics: enantiomerically pure chiral crystals based on trans -1,2-cyclohexanediol. CrystEngComm, 2019, 21 (34), pp.5129-5136. 10.1039/c9ce00807a . hal-02301848

\section{HAL Id: hal-02301848 \\ https://hal.science/hal-02301848}

Submitted on 30 Nov 2020

HAL is a multi-disciplinary open access archive for the deposit and dissemination of scientific research documents, whether they are published or not. The documents may come from teaching and research institutions in France or abroad, or from public or private research centers.
L'archive ouverte pluridisciplinaire HAL, est destinée au dépôt et à la diffusion de documents scientifiques de niveau recherche, publiés ou non, émanant des établissements d'enseignement et de recherche français ou étrangers, des laboratoires publics ou privés. 


\title{
Molecular tectonics: enantiomerically pure chiral crystals based on trans-1,2 cyclohexanediol
}

Received 00th January 20xx, Accepted 00th January $20 x x$ DOI: $10.1039 / \times 0 \times x 00000 x$

\author{
Benjamin Forquin, ${ }^{\mathrm{a}}$ Julien Berthaud, ${ }^{\mathrm{a}}$ Abdelaziz Jouaiti, ${ }^{{ }^{*}}$ Nathalie Kyritskas, ${ }^{\mathrm{a}}$ \\ Sylvie Ferlay, ${ }^{{ }^{*}}$ Mir Wais Hosseini ${ }^{*}$
}

\begin{abstract}
Enantiomerically pure chiral trans-1,2-cyclohexanediol $((R, R)$ or $(S, S))$ based organic compounds $\mathbf{3 b}$-c bearing two benzoic acid moieties are self complementary units and thus self-assemble in the crystalline phase into isostructural crystals composed of $1 \mathrm{D}$ helical $\mathrm{H}$-bonded networks with opposite handedness. The helical strands form enantiomerically pure triple helices. The racemic mixture of the two chiral ligands $\mathbf{3 a}$ also self-assembles into a 1D achiral H-bonded networks displaying a zig-zag type geometry. Upon deprotonation, both chiral $\mathbf{3 b}$ and $\mathbf{3} \mathbf{c}$ bearing two carboxylate moieties behave as coordinating ligands. When combined with $\mathrm{Cd}\left(\mathrm{NO}_{3}\right)_{2}$ in the presence of ancillary $\mathrm{N}$ donor ligands such as Dabco $(1,4-$ Diazabicyclo[2.2.2] octane) or bipy $\left(4,4^{\prime}\right.$ bipyridine)), they lead to the formation of enantiomarically pure coordination networks. Whereas for both Cd-3b-Dabco and Cd-3c-Dabco) 1D networks, resulting from the interconnection of 2-2 metallamacrocycles by Dabco behaving as a linear connector, are observed, in the case of 4,4'Bipy connector (Cd-3b-Bipy and Cd-3c-Bipy) a 2D coordination network based on the interconnection of binuclear Cd(II) dimers by coordinating ligands and ancilary ligands is generated.
\end{abstract}

\section{Introduction}

In the last years, due to their potential applications, Chiral Coordination Polymers (CCPs), ${ }^{1,2,3,4,5}$ a subclass of $\mathrm{CPs}^{6,7,8}$ also called MOFs or solid-state porous materials, ${ }^{9,10}$ have attracted increasing attention. The rational design and construction of enantiomerically pure coordination polymers still remain challenging, representing an ambitious goal for synthetic chemists. In principle, for the generation of CCPs, three strategies have been developed: (i) combinations of chiral coordinating ligands with metal centres ${ }^{11,12,13}$, (ii) combinations of achiral ligands and metal nodes in a chiral medium (solvent, template, etc) ${ }^{14}$, (iii) combination of achiral components undergoing spontaneous resolution. ${ }^{15,16,17}$ For the first strategy, a variety of chiral ligands bearing asymmetric carbon centres, for example, ${ }^{18,19}$ or chiral-at-metal metallaligands have been used. ${ }^{20,21,22,23,24}$ Chiral CCPs may find applications for enantioselective separation and/or adsorption, 25,26,27,28,29,30,31 asymmetric catalysis, ${ }^{32,33,34}$ and sensing. ${ }^{35}$ Porous chiral coordination polymers with large channels are of particular interest for the above mentioned applications. $36,37,38,39,40$

\footnotetext{
a. Molecular Tectonics Laboratory, University of Strasbourg, CNRS, CMC UMR 7140, F-67000 Strasbourg, France

See DOI: $10.1039 / x 0 x x 00000 x$

+ Electronic Supplementary Information (ESI) available: XRPD patterns for $\mathbf{3 b}$ and 3c and TGA traces for Cd-3b-Dabco and Cd-3b-Bipy.
}

For the formation of robust coordination polymers, ligands bearing carboxylate coordinating groups have been widely used, since the diverse coordinating modes they display may lead to interesting networks with various dimensionalities and topologies. ${ }^{41}$ The combination of chiral ligands bearing carboxylate coordinating groups has led to the formation of robust CCPs. Along this line, we have designed a pair of new chiral ligands (3b and $\mathbf{3 c}$, see figure 1 ) bearing benzoic/ate coordinating groups, based on the racemic trans-1,2cyclohexanediol 3a. Cyclohexanediol may be obtained as pure chiral compound $((\mathrm{R}, \mathrm{R})$ (1b- or $(\mathrm{S}, \mathrm{S})$-trans-1,2-cyclohexanediol 1c) as shown in figure 1 or as a racemic mixture (trans-1,2cyclohexanediol, 1a).

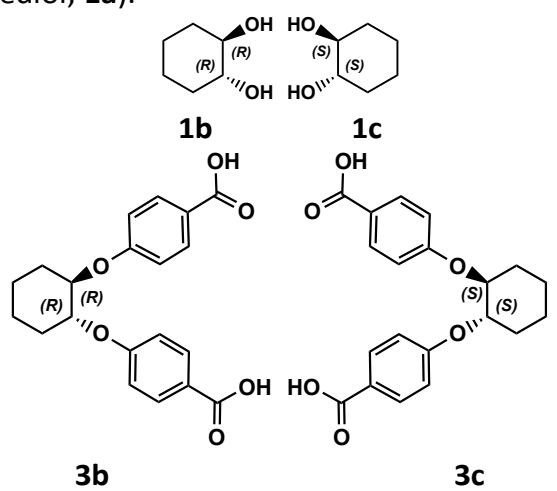

Figure 1: Both enantiomers of the chiral trans-1,2-cyclohexanediol starting material $\mathbf{1 b}$ and $\mathbf{1} \mathbf{c}$ (top) and the two enantiomerically pure compounds $\mathbf{3 b}$ and $\mathbf{3 c}$ (bottom) bearing two benzoic acids groups. The racemic mixture of the starting materials and of ligands are named $\mathbf{1} \mathbf{a}$ and $\mathbf{3 a}$ respectively. 
Chiral compounds $\mathbf{3 b}$ and $\mathbf{3 c}$ (figure 1 ) are based on chiral $(R, R)$ and $(S, S)$-trans-1,2-cyclohexanediol $\mathbf{1 b}$ and $\mathbf{1 c}$ respectively equipped with two benzoic acid units. An ether junction is used to interconnect the cyclohexyl moiety and benzoic acid units (Figure 1).

The trans-cycloheaxandiol moieties has already been used as a platform for the design of $\mathrm{V}$-shape ligands bearing two pyridyl units using ester junctions between the chiral scaffold and the coordinating sites. Their combination with $\mathrm{ZnSiF}_{6}$, was shown to afford enantiomerically pure crystals, for example. ${ }^{42}$

We report here on the synthesis of two enantiomerically pure compounds based on trans-1,2-cyclohexanediol and bearing carboxylic groups, their structural investigation by X-ray diffraction on single crystal and their combinations with $\mathrm{Cd}(\mathrm{II})$ cations together with ancillary $\mathrm{N}$ donor ligands like Dabco $(1,4-$ Diazabicyclo[2.2.2] octane) or Bipy (4,4'bipyridine).

\section{Experimental section}

\section{Characterization techniques}

${ }^{1} \mathrm{H}-\mathrm{NMR}$ and ${ }^{13} \mathrm{C}-\mathrm{NMR}$ spectra were recorded at room temperature on Bruker ( 400 or $500 \mathrm{MHz}$ ) NMR spectrometers by the shared NMR Service of the faculty of chemistry of the Strasbourg University.

Mass spectra (ESI) were recorded on a MicroTOF-Q (Bruker) equipped with an electrospray source.

CD spectra were recorded on a JASCO J-810 spectropolarimeter. Data were collected over a wavelength range of $200-400 \mathrm{~nm}$, at a scan speed of $50 \mathrm{~nm} / \mathrm{min}$, bandwidth of $1 \mathrm{~nm}$ and data pitch of $0.1 \mathrm{~nm}$. Samples were measured at RT $\left(23^{\circ} \mathrm{C}\right)$ and at given concentrations using a $10 \mathrm{~mm}$ path length cuvette (Starna Ltd.) Elemental analyses were performed by the Service de Microanalyses de la Fédération de Recherche Chimie, Université de Strasbourg, Strasbourg, France.

\section{Synthesis}

General: All reagents were purchased from commercial sources and used without further purification.

Bis-benzonitrile, 4,4'-[trans-1,2-cyclohexanediylbis(oxy)] $(2 \mathrm{a}, 2 \mathrm{~b}(1 \mathrm{R}, 2 \mathrm{R})$ and $2 \mathrm{c}(1 \mathrm{~S}, 2 \mathrm{~S}))$

Under an argon atmosphere, Trans-1,2-cyclohexanediol 1a (or (S,S)-trans-1,2-cyclohexanediol $\mathbf{1 b}$ or (R,R)-trans-1,2cyclohexanediol 1c) $(1.0 \mathrm{~g}, 8.6 \mathrm{mmol})$ was dissolved in $20 \mathrm{~mL}$ of dry DMF. NaH (1.0 g, $25 \mathrm{mmol}, 60 \%$ dispersion in mineral oil) was added. The reaction was heated at $60^{\circ} \mathrm{C}$ for $15 \mathrm{~min}$ before 4-fluorobenzonitrile ( $3.13 \mathrm{~g}, 25.8 \mathrm{mmol}$ ) was added and the reaction mixture was further heated at $120{ }^{\circ} \mathrm{C}$ for $48 \mathrm{~h}$. The solvent was removed and the crude product was dissolved in 30 $\mathrm{mL}$ of $\mathrm{CH}_{2} \mathrm{Cl}_{2}$, the organic phase was washed with aqueous $\mathrm{NH}_{4} \mathrm{Cl}$ (10\%). The organic phase was collected, dried over $\mathrm{MgSO}_{4}$ and evaporated to dryness. The remaining solid was purified by flash column chromatography on $\mathrm{SiO}_{2}\left(\mathrm{CH}_{2} \mathrm{Cl}_{2}\right)$. The solid was washed twice with $\mathrm{MeOH}$ and $\mathrm{Et}_{2} \mathrm{O}(10 \mathrm{ml})$ respectively affording compounds $\mathbf{2 a}, \mathbf{2} \mathbf{b}$ and $\mathbf{2 c}$ as white solids in $\mathbf{7 4 , 4 6}$ and $61 \%$. Yields respectively.

\section{Compound 2a}

${ }^{1} \mathrm{H}-\mathrm{RMN}\left(400 \mathrm{MHz}, \mathrm{CDCl}_{3}, 25^{\circ} \mathrm{C}\right): \delta(\mathrm{ppm})=7.51(\mathrm{~d}, 4 \mathrm{H}, J=8.8$ $\mathrm{Hz}) ; 6.92(\mathrm{~d}, 4 \mathrm{H}, J=8.8 \mathrm{~Hz}) ; 4.44(\mathrm{~m}, 2 \mathrm{H}) ; 2.20(\mathrm{~m}, 2 \mathrm{H}) ; 1.83$ $(\mathrm{m}, 2 \mathrm{H}) ; 1.60(\mathrm{~m}, 2 \mathrm{H}) ; 1.42(\mathrm{~m}, 2 \mathrm{H})$;

${ }^{13} \mathrm{C}-\mathrm{RMN}\left(125 \mathrm{MHz}, \mathrm{CDCl}_{3}, 25^{\circ} \mathrm{C}\right): \delta(\mathrm{ppm})=23.3 ; 29.9 ; 79.2$; $104.4 ; 116.5 ; 119.3 ; 134.1 ; 161.6$.

\section{Compound $\mathbf{2 b}$}

${ }^{1} \mathrm{H}-\mathrm{RMN}\left(400 \mathrm{MHz}, \mathrm{CDCl}_{3}, 25^{\circ} \mathrm{C}\right): \delta(\mathrm{ppm})=7.51(\mathrm{~d}, 4 \mathrm{H}, J=8.8$ $\mathrm{Hz}) ; 6.92(\mathrm{~d}, 4 \mathrm{H}, J=8.8 \mathrm{~Hz}) ; 4.44(\mathrm{~m}, 2 \mathrm{H}) ; 2.20(\mathrm{~m}, 2 \mathrm{H}) ; 1.83$ $(\mathrm{m}, 2 \mathrm{H}) ; 1.60(\mathrm{~m}, 2 \mathrm{H}) ; 1.42(\mathrm{~m}, 2 \mathrm{H})$;

${ }^{13} \mathrm{C}-\mathrm{RMN}\left(125 \mathrm{MHz}, \mathrm{CDCl}_{3}, 25^{\circ} \mathrm{C}\right): \delta(\mathrm{ppm})=23.3 ; 29.9 ; 79.2$; $104.4 ; 116.5 ; 119.3 ; 134.1 ; 161.6$.

HRMS (ESI): $m / z$ calcd. for $\mathrm{C}_{20} \mathrm{H}_{18} \mathrm{~N}_{2} \mathrm{O}_{2}$ [M-H]: 318.14; found: Compound 2c

${ }^{1} \mathrm{H}-\mathrm{RMN}\left(400 \mathrm{MHz}, \mathrm{CDCl}_{3}, 25^{\circ} \mathrm{C}\right): \delta(\mathrm{ppm})=7.51(\mathrm{~d}, 4 \mathrm{H}, J=8.8$ $\mathrm{Hz}) ; 6.92(\mathrm{~d}, 4 \mathrm{H}, J=8.8 \mathrm{~Hz}) ; 4.44(\mathrm{~m}, 2 \mathrm{H}) ; 2.20(\mathrm{~m}, 2 \mathrm{H}) ; 1.83$ $(\mathrm{m}, 2 \mathrm{H}) ; 1.60(\mathrm{~m}, 2 \mathrm{H}) ; 1.42(\mathrm{~m}, 2 \mathrm{H})$;

${ }^{13} \mathrm{C}-\mathrm{RMN}\left(125 \mathrm{MHz}, \mathrm{CDCl}_{3}, 25^{\circ} \mathrm{C}\right): \delta(\mathrm{ppm})=23.3 ; 29.9 ; 79.2$; $104.4 ; 116.5 ; 119.3 ; 134.1 ; 161.6$.

\section{Bis-benzoic acid, 4,4'-[trans-1,2-cyclohexanediylbis(oxy)] (3a, 3b (1R,2R) and 3c(1S,2S))}

An aqueous $\mathrm{NaOH}$ solution ( $62 \mathrm{mmol}, 12 \mathrm{mM}, 5 \mathrm{~mL}$ ) was added to a EtOH solution $(10 \mathrm{~mL})$ of $\mathbf{2 a}, \mathbf{2} \mathbf{b}$ or $\mathbf{2 c}(1 \mathrm{~g}, 3.1 \mathrm{mmol}$. The mixture was refluxed for $24 \mathrm{~h}$. After evaporation, $\mathrm{H}_{2} \mathrm{O}$ was added ( $15 \mathrm{~mL}$ ) and the mixture acidified using an aqueous $37 \%$ $\mathrm{HCl}$ solution (10 mL). The precipitate thus formed was filtered and washed with $\mathrm{H}_{2} \mathrm{O}(2 \times 10 \mathrm{~mL})$. After drying under vacuum, pure compounds $\mathbf{3 a}, \mathbf{3} \mathbf{b}$ and $\mathbf{3} \mathbf{c}$ were obtained as white solids in quantitative yield.

\section{Compound 3a}

${ }^{1} \mathrm{H}-\mathrm{RMN}\left(400 \mathrm{MHz}, \mathrm{DMSO}-\mathrm{d}_{6}, 25^{\circ} \mathrm{C}\right): \delta(\mathrm{ppm})=12.62(\mathrm{~s}, 2 \mathrm{H})$, $7.88(\mathrm{~d}, 4 \mathrm{H}, J=8.8 \mathrm{~Hz}) ; 7.00(\mathrm{~d}, 4 \mathrm{H}, J=8.8 \mathrm{~Hz}) ; 4.61(\mathrm{~m}, 2 \mathrm{H})$; $2.14(\mathrm{~m}, 2 \mathrm{H}) ; 1.70(\mathrm{~m}, 2 \mathrm{H}) ; 1.46(\mathrm{~m}, 4 \mathrm{H}) ;{ }^{13} \mathrm{C}-\mathrm{RMN}(125 \mathrm{MHz}$, DMSO-d $\left.6,25{ }^{\circ} \mathrm{C}\right): \delta(\mathrm{ppm})=22.8 ; 29.5 ; 78.3 ; 115.2 ; 122.9$; $131.3 ; 161.5 ; 167.0$.

HRMS (ESI): $\mathrm{m} / \mathrm{z}$ calcd. for $\mathrm{C}_{20} \mathrm{H}_{20} \mathrm{O}_{6}[\mathrm{M}-\mathrm{K}]:$ 395.089; found: 395.087

Anal. Calcd. for $\mathrm{C}_{20} \mathrm{H}_{20} \mathrm{O}_{6}$ : $\mathrm{C}, 67.4 \%, \mathrm{H}, 5.66 \%$; Found: $\mathrm{C}, 67.04 \%$, H, 5.52\%.

\section{Compound 3b}

${ }^{1} \mathrm{H}-\mathrm{RMN}\left(400 \mathrm{MHz}, \mathrm{DMSO}-\mathrm{d}_{6}, 25^{\circ} \mathrm{C}\right): \delta(\mathrm{ppm})=12,62(\mathrm{~s}, 2 \mathrm{H})$, $7,88(\mathrm{~d}, 4 \mathrm{H}, J=8.8 \mathrm{~Hz}) ; 7,00(\mathrm{~d}, 4 \mathrm{H}, J=8.8 \mathrm{~Hz}) ; 4,61(\mathrm{~m}, 2 \mathrm{H})$; $2,14(\mathrm{~m}, 2 \mathrm{H}) ; 1,70(\mathrm{~m}, 2 \mathrm{H}) ; 1,46(\mathrm{~m}, 4 \mathrm{H}) ;{ }^{13} \mathrm{C}-\mathrm{RMN}(125 \mathrm{MHz}$, 
DMSO- $\left.\mathrm{d}_{6}, 25{ }^{\circ} \mathrm{C}\right): \delta(\mathrm{ppm})=22,8 ; 29,5 ; 78,3 ; 115,2 ; 122,9$; 131,$3 ; 161,5 ; 167,0$.

HRMS (ESI): $\mathrm{m} / \mathrm{z}$ calcd. for $\mathrm{C}_{20} \mathrm{H}_{20} \mathrm{O}_{6}$ [M-K]: 395.089; found: 385.090

Anal. Calcd. for $\mathrm{C}_{20} \mathrm{H}_{20} \mathrm{O}_{6}$ : C, 67.41\%, H, 5.66\%; Found: C, 67.86\%, $\mathrm{H}, 5.45 \%$.

CD spectra see figure 3.

\section{Compound 3c}

${ }^{1} \mathrm{H}-\mathrm{RMN}\left(400 \mathrm{MHz}, \mathrm{DMSO}-\mathrm{d}_{6}, 25^{\circ} \mathrm{C}\right): \delta(\mathrm{ppm})=12.62(\mathrm{~s}, 2 \mathrm{H})$, $7.88(\mathrm{~d}, 4 \mathrm{H}, J=8.8 \mathrm{~Hz}) ; 7.00(\mathrm{~d}, 4 \mathrm{H}, J=8.8 \mathrm{~Hz}) ; 4.61(\mathrm{~m}, 2 \mathrm{H})$; $2.14(\mathrm{~m}, 2 \mathrm{H}) ; 1.70(\mathrm{~m}, 2 \mathrm{H}) ; 1.46(\mathrm{~m}, 4 \mathrm{H}) ;{ }^{13} \mathrm{C}-\mathrm{RMN}(125 \mathrm{MHz}$, DMSO-d $\left.6,25{ }^{\circ} \mathrm{C}\right): \delta(\mathrm{ppm})=22.8 ; 29.5 ; 78.3 ; 115.2 ; 122.9$; $131.3 ; 161.5 ; 167.0$.

HRMS (ESI): $\mathrm{m} / \mathrm{z}$ calcd. for $\mathrm{C}_{20} \mathrm{H}_{20} \mathrm{O}_{6}$ [M-K]: 395.089; found: 395.087.

Anal. Calcd. for $\mathrm{C}_{20} \mathrm{H}_{20} \mathrm{O}_{6}$ : C, 67.41\%, H, 5.66\%; Found: C, 67.92\%, H, 5.37\%.

CD spectra see figure 3.

\section{Crystallisations conditions}

A vial containing $0.5 \mathrm{~mL}$ of $\mathrm{CHCl}_{3}$ solution of $3 a, 3 b$ or $3 c(5 \mathrm{mg}$, $4.55 \times 10^{-3} \mathrm{mmol}$ ) was placed in a sealed beaker containing $\mathrm{CH}_{3} \mathrm{OH}$. Slow vapour diffusion at $\mathrm{RT}$ of $\mathrm{CH}_{3} \mathrm{OH}$ produced after several days colorless crystals suitable for $\mathrm{X}$-ray diffraction.

\section{Cd-3b-dabco or Cd-3c-dabco}

$3 \mathrm{ml}$ of a $\mathrm{H}_{2} \mathrm{O} / \mathrm{EtOH}(1 / 1)$ mixture containing compound $\mathbf{3 b}$ (or 3c) $\left(10 \mathrm{mg}, 28 \times 10^{-3} \mathrm{mmol}\right), \mathrm{Cd}\left(\mathrm{NO}_{3}\right)_{2}\left(6.6 \mathrm{mg}, 28 \times 10^{-3} \mathrm{mmol}\right)$, Dabco $\left(3.2 \mathrm{mg}, 28 \times 10^{-3} \mathrm{mmol}\right.$ ) and two drops of $\mathrm{Et}_{3} \mathrm{~N}$ was placed in a sealed vial. After one week at $100{ }^{\circ} \mathrm{C}$, the crystallization tube was cooled to room temperature affording colourless single crystals.

Due to the presence of different volatile solvents in the crystals, it was not possible to obtain a reliable Elemental Analysis.

\section{Cd-3b-Bipy or Cd-3c-Bipy:}

$3 \mathrm{~mL}$ of DMF containing compound $\mathbf{3 b}$ (or $\mathbf{3 c}$ ) (10 mg, $28 \times 10^{-3}$ $\mathrm{mmol}), \mathrm{Cd}\left(\mathrm{NO}_{3}\right)_{2}\left(6.6 \mathrm{mg}, 28 \times 10^{-3} \mathrm{mmol}\right)$, bipy $(8.7 \mathrm{mg}, 56 \times 10$ ${ }^{3} \mathrm{mmol}$ ) was placed in a sealed vial. After two day at $100{ }^{\circ} \mathrm{C}$, the crystallization tube was cooled to room temperature affording colourless single crystals.

Again, due to the presence of different volatile solvents in the crystals, it was not possible to obtain a reliable Elemental Analysis.

\section{Structural studies}

\section{Single-Crystal Studies}

Data were collected at $173(2) \mathrm{K}$ on a Bruker Apex-II-CCD diffractometer equipped with an Oxford Cryosystem liquid $\mathrm{N}_{2}$ device, using graphite-monochromated Mo-K $\alpha(\lambda=0.71073 \AA$ A radiation. For all structures, diffraction data were corrected for absorption. Structures were solved using SHELXS-97 and refined by full matrix least-squares on $F^{2}$ using SHELXL-97. The hydrogen atoms were introduced at calculated positions and refined using a riding model. ${ }^{43}$ They can be obtained free of charge from the Cambridge Crystallographic Data Centre via www.ccdc.cam.ac.uk/datarequest/cif. CCDC: 19083031908309: 1908303 (3a), 1908304 (3b), 1908305 (Cd-3c-Bipy), 1908306 (Cd-3b-Bipy), 1908307 (3c), 1908308 (Cd-3b-dabco), 1908309 (Cd-3c-dabco).

\section{Powder diffraction studies (PXRD)}

Diagrams were collected on a Bruker D8 diffractometer using monochromatic $\mathrm{CU}-\mathrm{K} \alpha$ radiation with a scanning range between 4 and $40^{\circ}$ using a scan step size of $8 \% \mathrm{mn}$.

As already demonstrated and currently admitted, for all compounds, discrepancies in intensity between the observed and simulated patterns are due to preferential orientations of the microcrystalline powders.

\section{Results and discussion}

\section{Synthesis of 3a-c}

The synthesis of enantiomerically compounds $\mathbf{3} \mathbf{b}$ and $\mathbf{3 c}$ and their racemic mixture 3a was achieved in 2 steps, as shown in the synthetic scheme shown in figure 2.

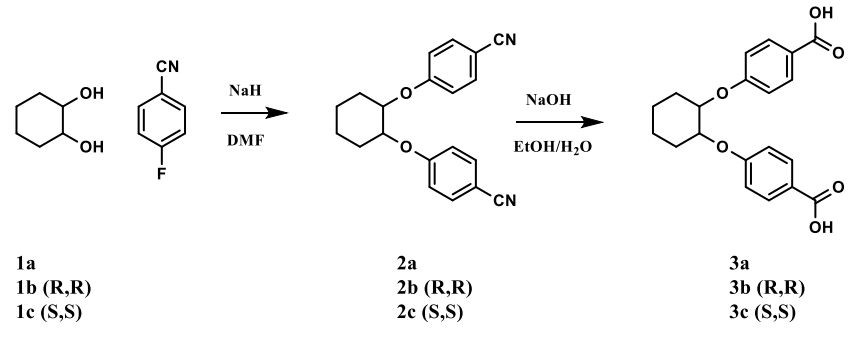

Figure 2. Synthetic pathway followed for the synthesis of the racemic mixture $\mathbf{3 a}$ and enantiomerically pure ligands $\mathbf{3 b}$ and $\mathbf{3} \mathbf{c}$.

Starting with either the racemic mixture of trans-1,2cyclohexanediol 1a or enantiomerically pure molecules $(R, R)$ trans-1,2-cyclohexanediol (1b) or (S,S)-trans-1,2cyclohexanediol (1c), the condensation with 4fluorobenzonitrile in DMF in the presence of $\mathrm{NaH}$ as base afforded the nitrile intermediate $\mathbf{2 a}$ ( $74 \%), \mathbf{2 b}(46 \%)$ and $\mathbf{2 c}$ (61 \%) respectively. Their hydrolysis in $\mathrm{EtOH} / \mathrm{H}_{2} \mathrm{O}$ by $\mathrm{NaOH}$ led quantitatively to the targeted ligands $\mathbf{3 a}, \mathbf{3 b}$ and $\mathbf{3 c}$ (Figure 2). All three compounds $\mathbf{3 a - c}$ were fully characterized in solution by common techniques and in the solid state by $\mathrm{X}$ ray diffraction on single crystals.

The enantiomerically pure ligands $\mathbf{3 b}$ and $\mathbf{3 c}$ were also characterized by $\mathrm{CD}$ spectroscopy in solution in $\mathrm{CHCl}_{3}$ (Figure 3 ). 


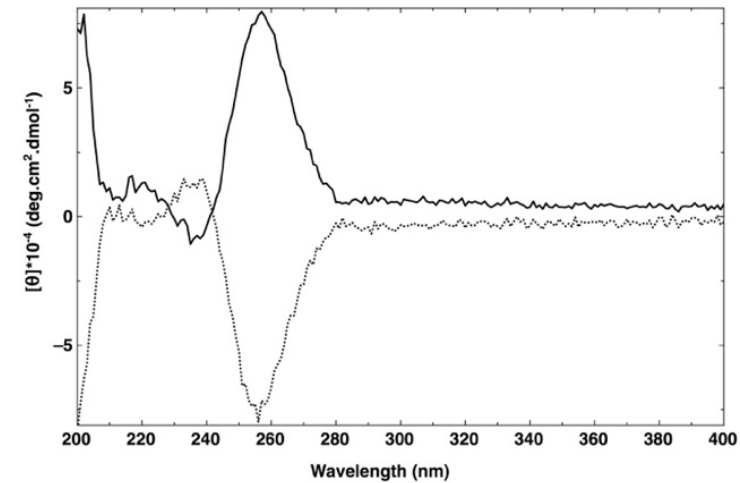

Figure 3. Circular Dichroism spectra of $\mathbf{3 b}$ (black solid line) and $\mathbf{3 c}$ (black dashed line) in $\mathrm{CHCl}_{3}$ at $\mathrm{RT}$.

\section{Structures of 3a-c in the solid-state}

Crystals of 3a-c have been obtained by slow vapor diffusion of $\mathrm{MeOH}$ into a $\mathrm{CHCl}_{3}$ solution containing the racemic mixture $\mathbf{3 a}$ or the chiral ligands $\mathbf{3 b}$ or $\mathbf{3} \mathbf{c}$ (see experimental section). Whereas $\mathbf{3 b}$ and $\mathbf{3 c}$ crystallize in the monoclinic chiral space group $P 2_{1}, 3 a$, as expected, crystallizes in the monoclinic achiral $P 2_{1}$ /c space group (see crystallographic table 1 ). In all three cases, crystals are composed of the organic ligands without any solvent molecules. Compounds 3a-c are in their carboxylic form and thus behaves as self-complementary ligands forming $\mathrm{H}$ bonded dimers. ${ }^{44}$ Indeed, in all cases, a short $(\mathrm{C}=\mathrm{O})$ and a long (C-OH) bonds are observed (see table 2). The translation of carboxylic-carboxylic $\mathrm{H}$-bonded nodes leads to the formation of 1D networks.

As expected, the partially flexible 3a-c adopt a V-Shape with angles of $69.5^{\circ}$ for $\mathbf{3 b}, 68.9^{\circ}$ for $\mathbf{3 c}$ and $46.8^{\circ}$ for $\mathbf{3 a}$. The angles and distances observed for $3 a-c$ in the crystalline phase are in agreement with those observed for benzoic acid and cyclohexanediol derivatives and thus will not be further commented here.

For the racemic mixture $\mathbf{3 a}$, composed of $\mathbf{3 b}$ and $\mathbf{3 c}$, the formation of a zig-zag flat $\mathrm{H}$-bonded chain running along the $a$ axis is observed (figure 4 top left). Consecutive units possessing opposite chirality are interconnected by carboxylic/carboxylic interactions with O-O distances of 2.627(4) and 2.636(3) Å (see table 2).

In the crystal, the chains are superimposed along the $b$ and $c$ axis, as shown in figure 4 top left.
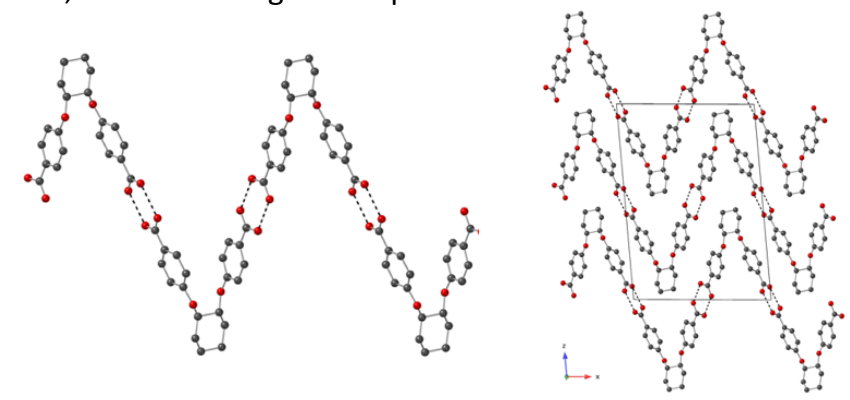

3a

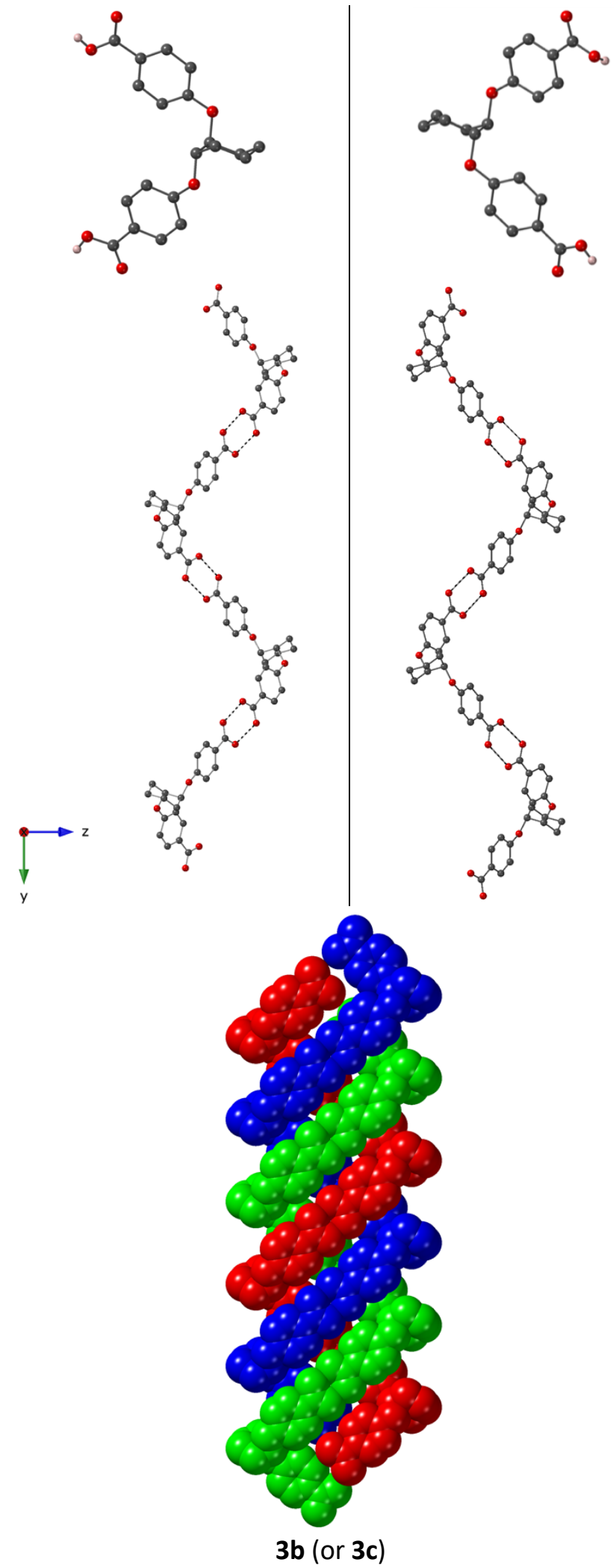

Figure 4. Representation of the $\mathrm{H}$-bond assembled molecular networks based on selfcomplementary 3a-c in the crystalline phase: racemic mixture 3a displaying a zig-zag $\mathrm{H}$ bonded chain (top and middle), together with the corresponding packing; enantiomerically pure compounds $\mathbf{3 b}$ and $\mathbf{3} \mathbf{b}$ forming helical $1 \mathrm{D} \mathbf{H}$-bonded chains organized as triple helices (bottom). For description of architectures see text.

In marked contrast with the racemic mixture $\mathbf{3 a}$, enantiomerically pure compounds $\mathbf{3 b}$ and $\mathbf{3 c}$ lead to 
isostructural crystals displaying opposite chirality. The translation of the carboxylic-carboxylic recognition motif (O-O distances of 2.583(3) and 2.622(3) ^ for 3b and 2.591(3) and 2.613(3) for 3c, table 2) between consecutive units leads to the formation of helical chains (figure 4). The helicoidal $\mathrm{H}$ bonded networks form triple helices as shown in figure 4. The triple helices are packed in a parallel fashion in the $x \mathrm{Oz}$ plane. $\mathrm{O}-\mathrm{H}-\mathrm{O}$ interactions are observed between two triple helices with an OO distance of 3.182 (4) $\AA$ and 3.184 (4) $\AA$ for $3 b$ and 3c respectively.

\begin{tabular}{|c|c|c|c|}
\hline & 3a & 3b & 3c \\
\hline & $1.241(3)$ & $1.258(4)$ & $1.267(3)$ \\
C-O (Å) & $1.263(3)$ & $1.268(3)$ & $1.268(3)$ \\
& $1.268(4)$ & $1.271(3)$ & $1.274(3)$ \\
& $1.295(3)$ & $1.276(3)$ & $1.275(3)$ \\
\hline \multirow{2}{*}{ O-O (Å) } & $2.627(4)$ & $2.583(3)$ & $2.591(3)$ \\
& $2.636(3)$ & $2.622(3)$ & $2.613(3)$ \\
\hline
\end{tabular}

Table 2. Main distances and angles for 3a-c.

The microcrystalline powders of the enantiomerically pure ligands $\mathbf{3 b}$ and $\mathbf{3} \mathbf{c}$ were also characterized by XRPD, showing the absence of crystallised racemic $\mathbf{3 a}$ in the solid for both compounds. (see figure S1 in ESI)

As described above, enantiomerically pure compounds $\mathbf{3 b}$ and 3c, as well their racemic mixture $\mathbf{3 a}$ in their protonated form, are self-complementary organic ligands leading to $\mathrm{H}$-bonded networks.

\section{Coordination properties of $3 b-c$}

3b and 3c, upon deprotonation offer two carboxylate coordination units and thus may be combined with metallic cations. For generating coordination networks, both chiral ligands $\mathbf{3 b}$ and $\mathbf{3} \mathbf{c}$ were combined with $\mathrm{Cd}(\mathrm{II})$ ( $\left.\mathrm{as} \mathrm{Cd}\left(\mathrm{NO}_{3}\right)_{2}\right)$ since cadmium in the oxidation state 2 favours the bidentate coordination mode of carboxylate bearing ligands. ${ }^{45,46}$

For the generation of Cd(II) coordination networks, ancillary $\mathrm{N}$-donor ligand such as Dabco (1,4-Diazabicyclo[2.2.2]octane) or $4,4^{\prime}$ bipyrine (bipy) have been used. The crystallization process was carried out under solvothermal conditions. It worth noting that, despite several attempts, it was not possible to obtain single crystals of coordination compound for the racemic mixture 3a.

\section{Cd-Dabco derivatives}

For $\mathbf{3 b}$ and $\mathbf{3 c}$, isostructural crystals $\mathbf{C d - 3 b - D a b c o ~ a n d ~ C d - 3 c - ~}$ Dabco $\left(\mathrm{C}_{20} \mathrm{H}_{18} \mathrm{O}_{6} \mathrm{Cd}\left(\mathrm{H}_{2} \mathrm{O}\right)\left(\mathrm{C}_{6} \mathrm{H}_{12} \mathrm{~N}_{2}\right)\right.$ (see experimental section) were obtained and characterized by $\mathrm{X}$-ray diffraction on single crystal. Both systems crystallize in an orthorhombic chiral space Group $P 22_{1} 2$ (table 3).

The crystal is composed of the chiral organic ligands $\mathbf{3 b}$ (or 3c), $\mathrm{Cd}^{2+}$ cation, $\mathrm{H}_{2} \mathrm{O}$ molecule coordinated to the metallic cation, and Dabco auxiliary ligands. The combination of the Vshape ligand ( $V$ angles of $50.1^{\circ}$ and $50.4^{\circ}$ for the Cd-3b-Dabco and Cd-3c-Dabco respectively) with $\mathrm{Cd}^{2+}$ cation leads to the formation of a binuclear metallamacrocycle, 47,48 resulting from the bis-bidentate behaviour of ligands $\mathbf{3 b}$ or $\mathbf{3 c}$. It is interesting to note, that in the coordination sphere of the metallic cation, a water molecule is also present.

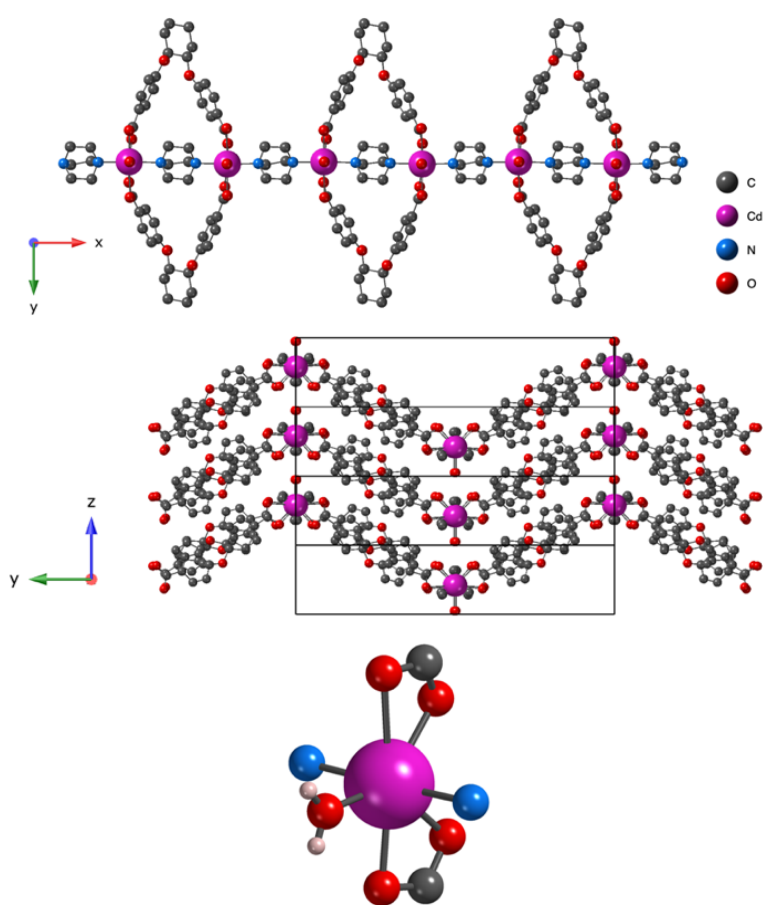

Figure 5. A portion of the chiral 1D coordination network obtained upon combining $\mathrm{Cd}\left(\mathrm{NO}_{3}\right)_{3}, \mathbf{3 b}$ or $\mathbf{3 c}$ and Dabco auxiliary ligand: metallamacrocycles connected by Dabco leading to a $1 \mathrm{D}$ chain along the $a$ axis (top), together with the corresponding packing (middle); coordination sphere around the metal centre (bottom).

The similar C-O distances observed for Cd-3b-Dabco and Cd3c-Dabco indicates that both ligands are in their carboxylate form (table 4). $\mathrm{Cd}$ (II) cations are hepta-coordinated and surrounded by two nitrogen atoms in trans disposition, belonging to different Dabco ligands, 2 carboxylate moieties acting as bidentate ligands and one water molecule (figure 5). In the structure, two types of ligand Dabco (one internal and one externa) are present. Consecutive metallamacrocycles are linked by external Dabco molecules, leading to a 1D coordination network running along the $a$ axis (figure 5). The distance between two consecutive $\mathrm{Cd}$ cations belonging to the same network varies between 7.209(5) and 7.342(5) A.

The 1D chains are stacked along the $a$ and $b$ axis (figure 5).

\begin{tabular}{|l|l|l|l|l|}
\hline & Cd-3b-Dabco & Cd-3c-Dabco & Cd-3b-Bipy & Cd-3c-Bipy \\
\hline C-O & $1.238(3)$ & $1.239(3)$ & $1.253(6)$ & $1.24(2)$ \\
& $1.259(3)$ & $1.259(3)$ & $1.255(6)$ & $1.242(17)$ \\
& $1.264(3)$ & $1.265(3)$ & $1.261(5)$ & $1.287(17)$ \\
& $1.282(2)$ & $1.284(3)$ & $1.262(5)$ & $1.288(18)$ \\
\hline Cd-O & $2.2981(14)$ & $2.3000(16)$ & $2.335(3)$ & $2.297(8)$ \\
& $2.3789(14)$ & $2.3847(15)$ & $2.380(3)$ & $2.321(10)$ \\
& $2.4533(16)$ & $2.4544(18)$ & $2.386(3)$ & $2.382(11)$ \\
& $2.6723(15)$ & $2.6755(18)$ & $2.378(3)$ & $2.390(14)$ \\
& & & $2.518(3)$ & $2.556(9)$ \\
\hline
\end{tabular}




\begin{tabular}{|l|l|l|l|l|}
\hline $\mathrm{Cd}-\mathrm{O}_{w}$ & $2.2830(14)$ & $2.2869(18)$ & - & - \\
\hline $\mathrm{Cd}-\mathrm{N}$ & $2.3187(17)$ & $2.3186(18)$ & $2.299(3)$ & $2.307(9)$ \\
& $2.3744(18)$ & $2.3748(19)$ & $2.332(4)$ & $2.332(9)$ \\
\hline $\mathrm{Cd}-\mathrm{Cd}$ & $7.209(5)$ and & $7.211(5)$ and & $3.830(3)$ & $3.823(4)$ \\
& $7.342(5)$ & $7.342(5)$ & & \\
\hline
\end{tabular}

Table 4 : Main distances for Cd-3b-Dabco, Cd-3c-Dabco, Cd-3b-Bipy and Cd-3c-Bipy

The purity of the Cd-3b-Dabco and Cd-3c-Dabco phases was investigated by PXRD on microcrystalline powder. For both compounds, a good match between the observed and simulated patterns from the XRD data was obtained (figure 6).

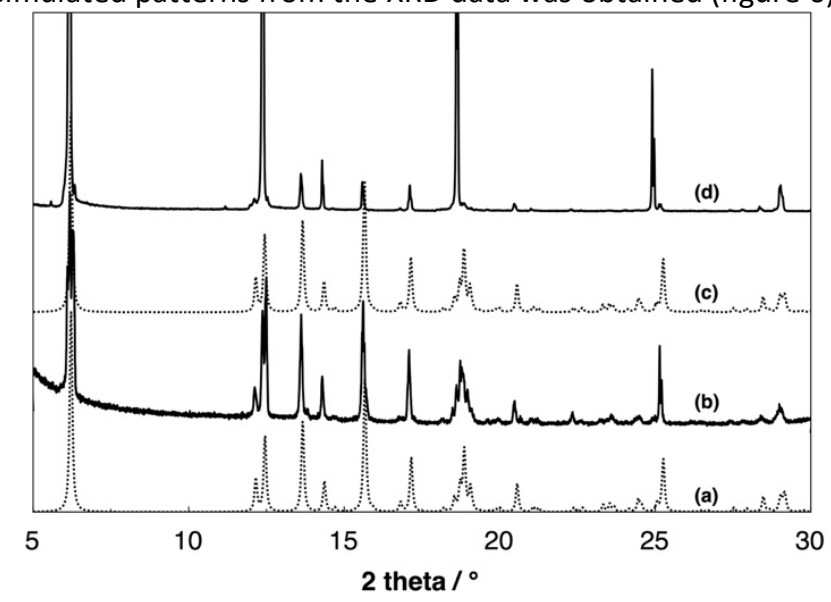

Figure 6. Comparison of the simulated XRPD diagrams ((a) for Cd-3b-Dabco and (c) for Cd-3c-Dabco) and recorded ((b) for Cd-3b-Dabco and (d) for Cd-3c-Dabco). Discrepancies in intensity between the observed and simulated patterns are due to preferential orientations of the microcrystalline powders.

\section{Cd-Bipyridine derivatives}

The combination of $\mathbf{3 b}$ or $\mathbf{3} \mathbf{c}$ with $\mathrm{Cd}^{2+}$ cation in the presence of 4, $4^{\prime}$-bipyridine again affords two isostructural crystals $\mathbf{C d - 3 b -}$ Bipy and Cd-3c-Bipy $\left(\mathrm{C}_{20} \mathrm{H}_{18} \mathrm{O}_{6} \mathrm{Cd}\left(\mathrm{C}_{10} \mathrm{H}_{8} \mathrm{~N}_{2}\right)\right.$ under solvothermal conditions (see experimental part). Both compounds crystallize in a monoclinic chiral space Group $\mathbf{C 2}$. The crystal contains $\mathbf{3 b}$ (or $3 c$ ) chiral organic $V$-shape ligands (angles of $21.3^{\circ}$ and $21.4^{\circ}$ for the Cd-3b-Bipy and Cd-3c-Bipy respectively), $\mathrm{Cd}^{2+}$ cation and the Bipy ancillary ligand (figure 7). Due to the presence of disordered solvent molecules in the crystal, the structures were refined by applying the squeeze command. ${ }^{49}$ A thick $2 \mathrm{D}$ architecture, with a metallic plane encapsulated in the $V$ shape organic ligands, resulting from the formation of $\mathrm{Cd}$-dimeric units is observed (figure 7, middle). The 4,4'-bipy ligands behave as pillars between the bimetallic nodes. Within the coordination network, the $\mathrm{Cd}-\mathrm{Cd}$ distances are equal to 3.830(3) and 3.823(4) $\AA$ for Cd-3b-Bipy and Cd-3c-Bipy, respectively. This corresponds to what is usually observed for $\mathrm{Cd}$ (II) carboxylate bridged dinuclear units. ${ }^{50}$ The bulky 2D system, parallel to the $x O y$ planes, are formed by bridging of dinuclear metallic units, along the $c$ axis, by the $V$ shape ligands $\mathbf{3 b}$ or $3 c$ and by linear $4,4^{\prime}$ bipyridine ligands in the $b$ direction (figure 7 top).

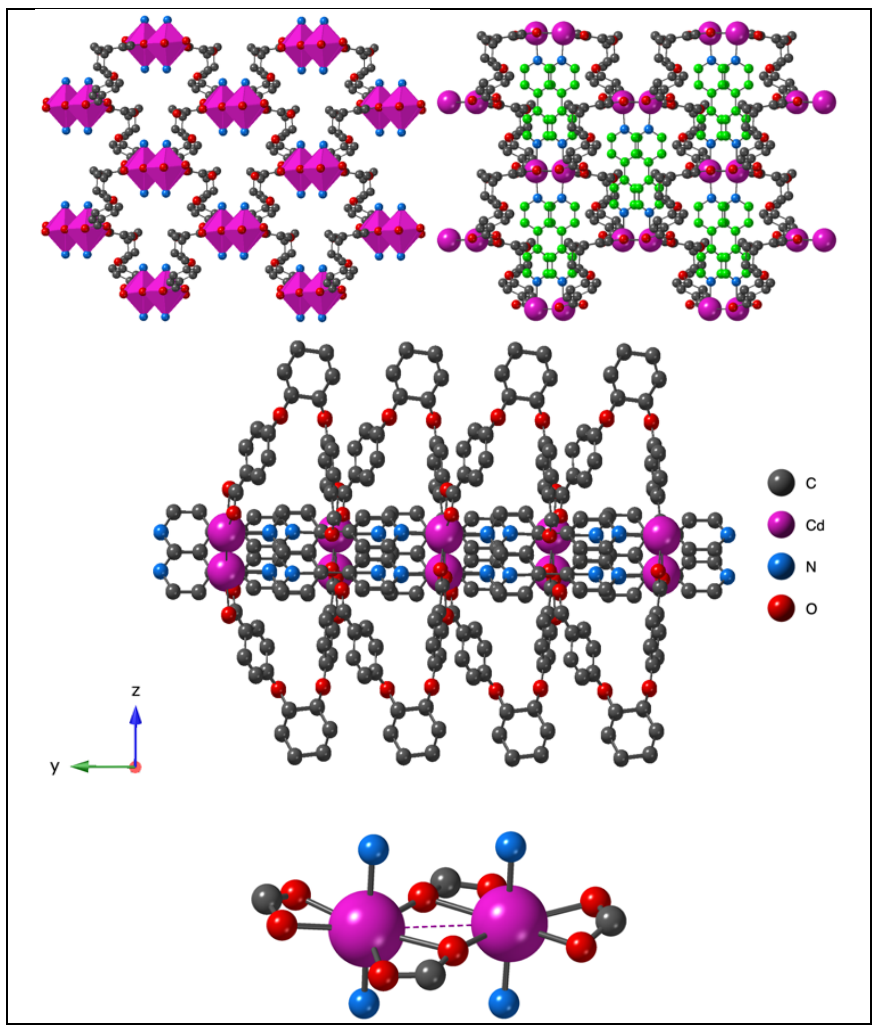

Figure 7. A portion of the chiral $\mathrm{Cd} 2 \mathrm{D}$ coordination network formed upon combination of $\mathrm{Cd}\left(\mathrm{NO}_{3}\right)_{3}, 3 \mathbf{b}-\mathbf{c}$ and bipy (represented in green) in the xOy plane: top, the thick $2 \mathrm{D}$ - in the yOz plane (middle); the coordination sphere around the binuclear nodes (bottom).

Again, similar C-O distances for Cd-3b-Bipy and Cd-3c-Bipy indicate the deprotonation of ligands $\mathbf{3 b}$ or $\mathbf{3 c}$ (table 4). The metallic enters are, as in the previous cases, hepta-coordinated and surrounded by two nitrogen atoms in trans position, belonging to 4,4' bipy ligands, three carboxylate moieties, one acting as a bidentate unit and the other two as bridges between the dimeric unit (figure 7). The bond distances around the metallic centres are reported in table 4.

The 2D arrays are stacked along the $c$ axis, some van der Waals contacts between ligands belonging to two adjacent planes are observed.

The purity of Cd-3b-Bipy and Cd-3c-Bipy phases was studied by PXRD on microcrystalline powder (figure 8 ) which revealed a good match between the recorded and the simulated pattern using XRD data. 


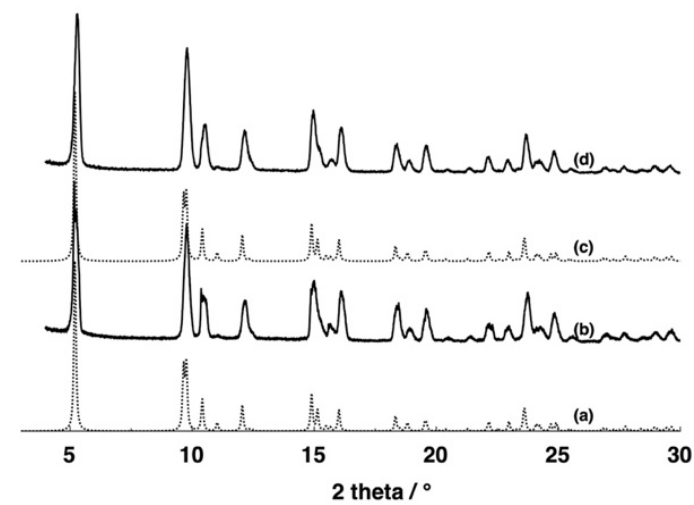

Figure 8. Comparison of the simulated XRPD diagrams ((a) for Cd-3b-Bipy and (c) for Cd3c- Bipy) and recorded ((b) for Cd-3b- Bipy and (d) for Cd-3c- Bipy). Discrepancies in intensity between the observed and simulated patterns are due to preferential orientations of the microcrystalline powders.

\section{Conclusions}

The synthesis of two enantiomerically pure compounds $\mathbf{3 b}$ and $\mathbf{3 c}$ and their racemic mixture $\mathbf{3 a}$, that are based on the (trans-1,2-cyclohexanediol bearing two benzoic groups, was achieved. The solid-state structures of these flexible V-shape dicarboxylic connectors was investigated by X-ray diffraction on single crystal. Owing to the self-complementary nature of the ligands resulting from the recognition of carboxylic sites, all three compounds lead to the formation of zigzag 1D H-bonded networks. As expected, crystals of the racemic mixture are achiral whereas the two enantiomerically pure ligands $\mathbf{3 b}$ and 3c, afford isostructural helical 1D networks with opposite handedness, organized in triple helical architectures.

Interestingly, the chiral ligands $\mathbf{3 b}$ and $\mathbf{3 c}$ in their deprotonated form lead, under solvothermal conditions, to the

1. K. Kim, M. Banerjee, M. Yoon and S. Das, in Topics in Current Chemistry, ed. M. Schröder, Springer, Berlin Heidelberg, 2010, ch. 7, 293, 115-153.

2. W. Lin, Top. Catal., 2010, 53, 869-875.

3. L. Ma and W. Lin, in Topics in Current Chemistry, ed. M. Schröder, Springer, Berlin Heidelberg, 2010, ch. 7, 293, 175205.

4. R. E. Morris and X. Bu, Nat. Chem., 2010, 2, 353-361.

5. K. K. Bisht, B. Parmar, Y. Rachuri, A. C. Kathalikattil and E. Suresh, CrystEngComm, 2015, 17, 5341-5356.

6. B. F. Abrahams, B. F. Hoskins and R. Robson, J. Am. Chem. Soc., 1991, 113, 3606-3607.

7. M. W. Hosseini, Acc. Chem. Res., 2005, 38, 313-323.

8. M. W. Hosseini, CrystEngComm, 2004, 6, 318-322.

9. Chem. Rev., 2012, 112, MOFs special issue.

10. Chem. Soc. Rev., 2014, 43, themed issue on MOFs.

11. E. V. Anokhina, Y. B. Go, Y. Lee, T. Vogt and A. J. Jacobson, J. Am. Chem. Soc., 2006, 128, 9957-9962.

12. R. Vaidhyanathan, D. Bradshaw, J. N. Rebilly, J. P. Barrio, J. A. Gould, N. G. Berry and M. J. Rosseinsky, Angew. Chem. Int. Ed., 2006, 45, 6495-6499.

13. W. Xuan, M. Zhang, Y. Liu, Z. Chen and Y. Cui, J. Am. Chem. Soc., 2012, 134, 6904-6907.

14. R. E. Morris, Chem. Commun., 2009, 2990-2998. formation of coordination networks when combined with $\mathrm{Cd}^{2+}$ cation in the presence of $\mathrm{N}$ donor ancillary ligands such as Dabco (Cd-3b-Dabco and Cd-3c-Dabco) or 4,4' Bipy (Cd-3b-Bipy and Cd-3c-Bipy) behaving as linear connectors. Chiral crystals of $\mathrm{Cd}$ 3b-Dabco and Cd-3c-Dabco are composed of 1D networks resulting from the interconnection of consecutive metallamacrocycles by bis monodentate Dabco, whereas in the case of Cd-3b-Bipy and Cd-3c-Bipy, a 2D network resulting from the interconnection of binuclear $\mathrm{Cd}(\mathrm{II})$ nodes by the chiral and ancillary ligands.

The formation of other enantiomerically pure coordination polymers using other metals is currently under investigation.

\section{Conflicts of interest}

There are no conflicts to declare.

\section{Acknowledgements}

We thank the University of Strasbourg, the C.N.R.S, the International centre for Frontier Research in Chemistry (icFRC), the Labex CSC (ANR-10-LABX-0026 CSC) within the Investissement d'Avenir program ANR-10-IDEX-0002-02, the Ministère de l'Enseignement Supérieur et de la Recherche for financial support.

\section{Notes and references}

15. X.-L. Tong, T.-L. Hu, J.-P. Zhao, Y.-K. Wang, H. Zhang and X.-H. Bu, Chem. Commun., 2010, 46, 8543-8545.

16. Q.-Y. Liu, Y.-L. Wang, N. Zhang, Y.-L. Jiang, J.-J. Wei and F. Luo, Cryst. Growth Des., 2011, 11, 3717-3720.

17. X. Tan, J. Zhan, J. Zhang, L. Jiang, M. Pan and C.-Y. Su, CrystEngComm, 2012, 14, 63-66.

18. L. Dong, W. Chu, Q. Zhu and R. Huang, Cryst. Growth Des., 2011, 11, 93-99.

19. P. Larpent, A. Jouaiti, N. Kyritsakas and M. W. Hosseini, Dalton Trans, 2014, 43, 166-172.

20. J. Chen and F. M. MacDonnell, Chem. Commun., 1999, 25292530

21. S. J. Garibay, J. R. Stork, Z. Wang, S. M. Cohen and S. G. Telfer, Chem. Commun., 2007, 4881-4883.

22. C. Xu, A. Guenet, N. Kyritsakas, J.-M. Planeix and M. W. Hosseini, Inorg. Chem., 2015, 54, 10429-10439.

23. Z.-H. Yan, D. Li and X.-B. Yin, Sci. Bull., 2017, 62, 1344-1354.

24. M. Enamullah, V. Vasylyeva, M. A. Quddus, M. K. Islam, S.-P. Höfert and C. Janiak, CrystEngComm, 2018, 20, 4724-4734.

25. J. S. Seo, D. Whang, H. Lee, S. I. Jun, J. Oh, Y. J. Jeon and K. Kim, Nature, 2000, 404, 982-986.

26. Y. Peng, T. Gong, K. Zhang, X. Lin, Y. Liu, J. Jiang and Y. Cui, Nat. Commun., 2014, 5, 4406. 
27. T. Sawano, N. C. Thacker, Z. Lin, A. R. Mclsaac and W. Lin, J. Am. Chem. Soc., 2015, 137, 12241-12248.

28. D. Asnaghi, R. Corso, P. Larpent, I. Bassanetti, A. Jouaiti, N. Kyritsakas, A. Comotti, P. Sozzani and M. W. Hosseini, Chem. Commun., 2017, 53, 5740-5743.

29. J. Guo, Y. Zhang, Y. Zhu, C. Long, M. Zhao, M. He, X. Zhang, J. Lv, B. Han and Z. Tang, Angew. Chem., 2018, 130, 6989-6993.

30. X. Han, J. Huang, C. Yuan, Y. Liu and Y. Cui, J. Am. Chem. Soc., 2018, 140, 892-895.

31. S. Das, S. Xu, T. Ben and S. Qiu, Angew. Chem. Int. Ed. 2018, 57, 8629-8633.

32. L. Ma, C. Abney and W. Lin, Chem. Soc. Rev., 2009, 38, 12481256.

33. L. Ma, J. M. Falkowski, C. Abney and W. Lin, Nat. Chem., 2010, 2, 838-846.

34. M. Yoon, R. Srirambalaji and K. Kim, Chem. Rev., 2012, 112, 1196-1231.

35. M. M. Wanderley, C. Wang, C.-D. Wu and W. Lin, J. Am. Chem. Soc., 2012, 134, 9050-9053.

36. D. Sun, Y. Ke, D. J. Collins, G. A. Lorigan and H.-C. Zhou, Inorg Chem., 2007, 46, 2725-2734.

37. D. N. Dybtsev, M. P. Yutkin, E. V. Peresypkina, A. V. Virovets, C. Serre, G. Férey and V. P. Fedin, Inorg. Chem., 2007, 46, 68436845.
38. W. J. Rieter, K. M. Pott, K. M. Taylor and W. Lin, J. Am. Chem. Soc., 2008, 130, 11584-11585.

39. Y. Liu, W. Xuan and Y. Cui, Adv. Mater., 2010, 22, 4112-4135.

40. Q. Zhu, T. Sheng, R. Fu, C. Tan, S. Hu and X. Wu, Chem. Commun., 2010, 46, 9001-9003.

41. S. R. Batten, S. M. Neville and D. R. Turner, in Coordination Polymers: Design, Analysis and Application, The Royal Society of Chemistry, Cambridge, 2009.

42. M-J. Lin, A. Jouaiti, P. Grosshans, N. Kyritsakas and M. W. Hosseini, Chem. Commun., 2011, 47, 7635-7637.

43. G. M. Sheldrick, Program for Crystal Structure Solution, University of Göttingen, Göttingen, Germany, 1997.

44. T. Steiner Angew. Chem. Int. Ed. 2002, 41, 48-76.

45. M.-D. Zhang, Y. Jiao, J. Li and M-D. Chen Mendeleev Commun., 2015, 25, 65-66.

46. L. Wang, M. Yang, G. Li, Z. Shi and S. Feng Inorg. Chem., 2006, 45, 2474-2478.

47. A. W. Maverick, S.C. Buckingham, Q. Yao, J. R. Bradbury and G. G. Stanley, J. Am. Chem. Soc. 1986, 108, 743-748.

48. C. H. M. Amijs, G. P. M. v. Klink and G. v. Koten, Dalton Trans., 2006, 308-327.

49. A. L. Spek, J. Appl. Crystallogr., 2003, 36, 7-13.

50. S. Shit, J. Chakraborty, B. Samanta, G. Pilet and S. Mitra, J. Mol. Struct., 2009, 919, 361-365. 


\section{ARTICLE}

Table 1. Crystallographic parameters for 3a-c recorded at $173 \mathrm{~K}$.

\begin{tabular}{|c|c|c|c|}
\hline & $3 a$ & $3 b$ & $3 c$ \\
\hline & Racemate & $(R, R)$ & $(\mathrm{S}, \mathrm{S})$ \\
\hline Empirical formula & $\mathrm{C}_{20} \mathrm{H}_{20} \mathrm{O}_{6}$ & $\mathrm{C}_{20} \mathrm{H}_{20} \mathrm{O}_{6}$ & $\mathrm{C}_{20} \mathrm{H}_{20} \mathrm{O}_{6}$ \\
\hline Formula weight $\mathrm{g} / \mathrm{mol}$ & 356.36 & 356.36 & 356.36 \\
\hline Crystal system & Monoclinic & Monoclinic & Monoclinic \\
\hline Space group & $\mathrm{P} 21 / \mathrm{c}$ & $\mathrm{P} 21$ & P 21 \\
\hline $\mathrm{a}(\AA \cap)$ & $15.001(2)$ & $9.2808(5)$ & $9.2536(5)$ \\
\hline $\mathrm{b}(\AA)$ & $5.5536(5)$ & $7.6511(3)$ & $7.6512(3)$ \\
\hline$c(\AA)$ & $21.455(3)$ & $12.6946(6)$ & $12.6769(7)$ \\
\hline$\alpha(\operatorname{deg})$ & 90 & 90 & 90 \\
\hline$\beta($ deg $)$ & $95.230(2)$ & $108.142(2)$ & $108.093(2)$ \\
\hline$\gamma($ deg $)$ & 90 & 90 & 90 \\
\hline$V\left(\AA^{3}\right)$ & $1780.0(4)$ & $856.61(7)$ & $853.16(7)$ \\
\hline Z & 4 & 2 & 2 \\
\hline Colour & white & white & white \\
\hline Crystal dim (mm) & $0.120 \times 0.060 \times 0.060$ & $0.070 \times 0.060 \times 0.050$ & $0.060 \times 0.050 \times 0.050$ \\
\hline Dcalc $\left(\mathrm{gcm}^{-3}\right)$ & 1.330 & 1.382 & 1.387 \\
\hline$F(000)$ & 752 & 376 & 376 \\
\hline$\mu\left(\mathrm{mm}^{-1}\right)$ & 0.098 & 0.102 & 0.103 \\
\hline Wavelength $(\AA ̊)$ & 0.71073 & 0.71073 & 0.71073 \\
\hline Reflections collected & 10173 & 7396 & 8761 \\
\hline Independent reflections & $3816[\mathrm{R}$ (int) $=0.0415]$ & $3730[\mathrm{R}$ (int) $=0.0236]$ & $4095[\mathrm{R}$ (int) $=0.0255]$ \\
\hline Final R indices [I>2sigma(I)] & $\mathrm{R} 1=0.0562, \mathrm{wR} 2=0.1480$ & $\mathrm{R} 1=0.0401, \mathrm{wR2}=0.1164$ & $R 1=0.0451, w R 2=0.0756$ \\
\hline$R$ indices (all data) & $\mathrm{R} 1=0.1321, \mathrm{wR} 2=0.1973$ & $\mathrm{R} 1=0.0464, w R 2=0.1201$ & $R 1=0.0539, w R 2=0.0773$ \\
\hline Goodness-of-fit on $\mathrm{F}^{2}$ & 1.014 & 1.060 & 1.719 \\
\hline Largest diff. peak / hole $\left(\mathrm{e}^{-3}\right)$ & 0.163 and -0.208 & 0.359 and -0.292 & 0.249 and -0.254 \\
\hline
\end{tabular}


Table 3.Crystallographic parameters for Cd-3b-Dabco, Cd-3c-Dabco, Cd-3b-Bipy and Cd-3c-Bipy recorded at $173 \mathrm{~K}$

\begin{tabular}{|c|c|c|c|c|}
\hline & Cd-3b-Dabco & Cd-3c-Dabco & Cd-3b-Bipy & Cd-3c-Bipy \\
\hline & $(R, R)$ & $(S, S)$ & $(R, R)$ & $(S, S)$ \\
\hline Empirical formula & $\mathrm{C}_{26} \mathrm{H}_{32} \mathrm{CdN}_{2} \mathrm{O}_{7}$ & $\mathrm{C}_{26} \mathrm{H}_{32} \mathrm{CdN}_{2} \mathrm{O}_{7}$ & $\mathrm{C}_{30} \mathrm{H}_{26} \mathrm{CdN}_{2} \mathrm{O}_{6}$ & $\mathrm{C}_{30} \mathrm{H}_{26} \mathrm{CdN}_{2} \mathrm{O}_{6}$ \\
\hline Formula weight $\mathrm{g} / \mathrm{mol}$ & 596.93 & 596.93 & 622.93 & 622.93 \\
\hline Crystal system & Orthorhombic & Orthorhombic & Monoclinic & Monoclinic \\
\hline Space group & P 21212 & P 21212 & $\mathrm{C} 2$ & $\mathrm{C} 2$ \\
\hline $\mathrm{a}(\AA ̊)$ & $14.5475(6)$ & $14.5483(5)$ & $16.0435(14)$ & $15.6883(18)$ \\
\hline$b(\AA ̊)$ & $28.4089(12)$ & $28.4278(12)$ & $11.6969(8)$ & $11.7144(12)$ \\
\hline$c(\AA)$ & $6.1616(3)$ & $6.1660(2)$ & $18.4980(15)$ & $17.7770(18)$ \\
\hline$\alpha(\operatorname{deg})$ & 90 & 90 & 90 & 90 \\
\hline$\beta$ (deg) & 90 & 90 & $113.454(2)$ & 109.199(3) \\
\hline$\gamma($ deg $)$ & 90 & 90 & 90 & 90 \\
\hline $\mathrm{V}\left(\AA^{3}\right)$ & $2546.46(19)$ & $2550.11(16)$ & $3184.5(4)$ & $3085.3(6)$ \\
\hline $\mathrm{Z}$ & 4 & 4 & 4 & 4 \\
\hline Colour & white & white & white & white \\
\hline Crystal dim (mm) & $0.120 \times 0.120 \times 0.100$ & $0.080 \times 0.070 \times 0.070$ & $0.090 \times 0.080 \times 0.080$ & $0.040 \times 0.040 \times 0.040$ \\
\hline Dcalc $\left(\mathrm{gcm}^{-3}\right)$ & 1.557 & 1.555 & 1.299 & 1.341 \\
\hline$F(000)$ & 1224 & 1224 & 1264 & 1264 \\
\hline$\mu\left(\mathrm{mm}^{-1}\right)$ & 0.906 & 0.904 & 0.725 & 0.749 \\
\hline Wavelength $(\AA ̊)$ & 0.71073 & 0.71073 & 0.71073 & 0.71073 \\
\hline Reflections collected & 146392 & 37014 & 19760 & 5664 \\
\hline $\begin{array}{l}\text { Independent } \\
\text { reflections }\end{array}$ & $7046[R($ int $)=0.0331]$ & $7439[R$ (int) $=0.0315]$ & $8357[R$ (int) $=0.0429]$ & $5140[R($ int $)=0.0355]$ \\
\hline $\begin{array}{l}\text { Final R indices } \\
{[\mathrm{I}>2 \operatorname{sigma}(\mathrm{I})]}\end{array}$ & $\begin{array}{c}R 1=0.0204, w R 2= \\
0.0485\end{array}$ & $\begin{array}{c}\mathrm{R} 1=0.0245, \mathrm{wR} 2= \\
0.0559\end{array}$ & $\begin{array}{c}\mathrm{R} 1=0.0426, \mathrm{wR} 2= \\
0.0897\end{array}$ & $\begin{array}{c}\mathrm{R} 1=0.1084, \mathrm{wR} 2= \\
0.2562\end{array}$ \\
\hline R indices (all data) & $\begin{array}{c}\mathrm{R} 1=0.0215, w R 2= \\
0.0491\end{array}$ & $\begin{array}{c}\mathrm{R} 1=0.0309, w R 2= \\
0.0589\end{array}$ & $\begin{array}{c}\mathrm{R} 1=0.0572, \mathrm{wR} 2= \\
0.0959\end{array}$ & $\begin{array}{c}\mathrm{R} 1=0.1708, \mathrm{wR} 2= \\
0.3170\end{array}$ \\
\hline Goodness-of-fit on $F^{2}$ & 1.094 & 0.971 & 1.031 & 1.085 \\
\hline $\begin{array}{c}\text { Largest diff. peak / } \\
\text { hole }\left(e \AA^{-3}\right)\end{array}$ & 0.496 and -0.711 & 0.353 and -0.336 & 1.458 and -1.092 & 1.787 and -1.525 \\
\hline Flack parameter & $-0.012(4)$ & $-0.018(9)$ & $-0.009(16)$ & $0.04(10)$ \\
\hline
\end{tabular}




\section{Journal Name}

\section{Graphical Abstract}<smiles>O=C(O)c1ccc(O[C@@H]2CCCC[C@@H]2Oc2ccc(O[C@@H]3CCCC[C@H]3Oc3ccc(C(=O)O)cc3)cc2)cc1</smiles>
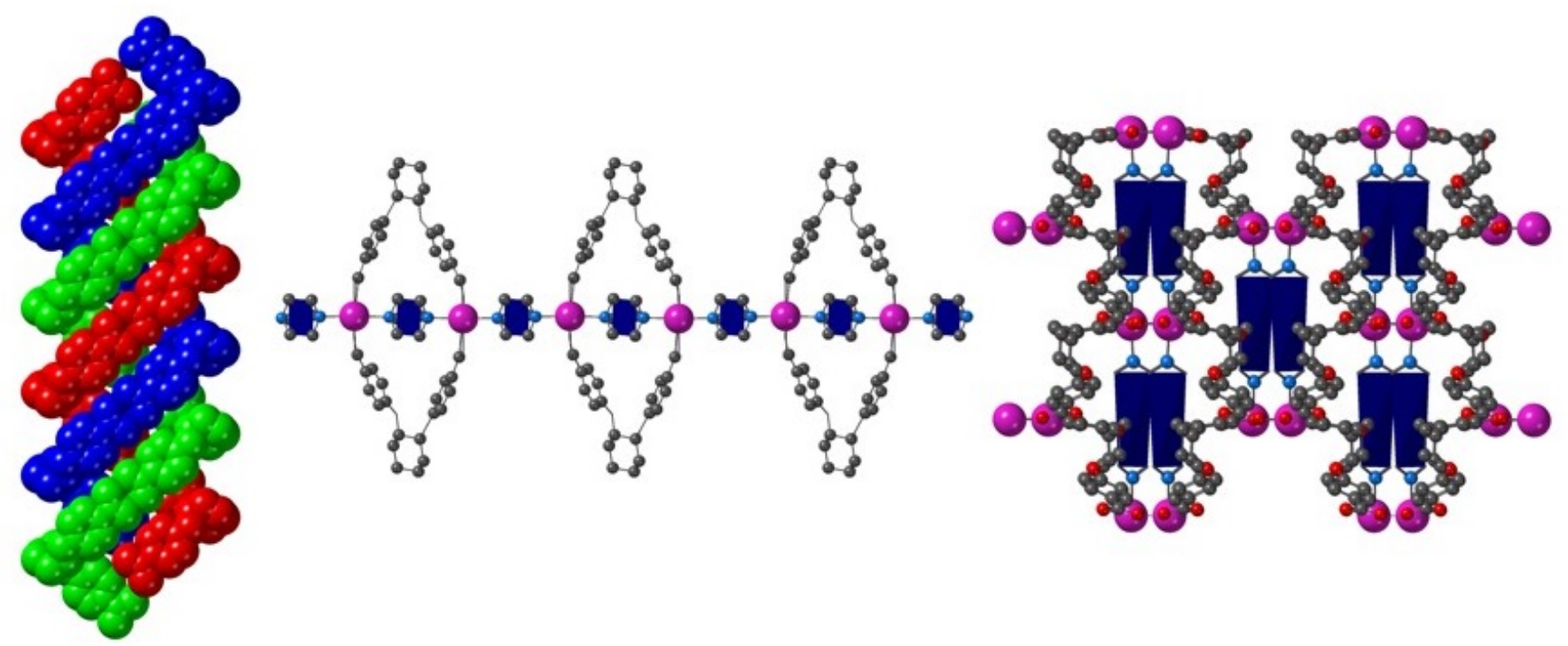